\title{
ANALYSIS OF THE IMPACT OF VEGETATION DISTRIBUTION, URBANIZATION, AND SOLAR RADIATION ON THE SEASONAL VARIATION OF THE URBAN HEAT ISLAND EFFECT IN CEBU CITY USING LANDSAT AND GLOBAL HORIZONTAL IRRADIANCE DATA
}

\author{
S. F. Cañete ${ }^{1}$, L. L. Schaap ${ }^{2}$, R. Andales ${ }^{2}$, R. E. S. Otadoy ${ }^{2,3}$ *, A. Blanco ${ }^{1,4}$, J. Babaan ${ }^{1}$, C. Cruz ${ }^{1}$ \\ ${ }^{1}$ Training Center for Applied Geodesy and Photogrammetry, University of the Philippines Diliman, Quezon City 1101, Philippines - \\ sfcanete@gmail.com, (jbbabaan, cacruz7)@up.edu.ph \\ ${ }^{2}$ Theoretical and Computational Sciences and Engineering Group, Dept. of Physics, University of San Carlos-Talamban Campus, \\ Nasipit, Talamban, Cebu City 6000, Philippines - (llsschaap.ls, ronelle.andales)@ gmail.com \\ ${ }^{3}$ Center for Geoinformatics and Environmental Solutions, University of San Carlos-Talamban Campus, Nasipit, Talamban, Cebu \\ City 6000, Philippines - rsotadoy@usc.edu.ph \\ ${ }^{4}$ Department of Geodetic Engineering, College of Engineering, University of the Philippines Diliman, Quezon City 1101, \\ Philippines-acblanco@up.edu.ph
}

\section{Commission IV}

KEY WORDS: Land surface temperature, remote sensing, normalized difference vegetation index, normalized difference built-up index

\begin{abstract}
:
The Urban Heat Island (UHI) phenomenon is a manifestation of the abnormal amount of heat generated in urban areas and anthropogenic land surface modifications. While urbanization can improve material comfort and be a boon to the economy, the accompanying problems associated with urbanization like the UHI effect has implications on health, demand for water and energy, and impacts the microclimate. Land surface temperature (LST), the Normalized Difference Vegetation Index (NDVI), and the Normalized Difference Built-up Index (NDBI) were calculated from historical remotely-sensed Landsat data from 2013 to present. The global horizontal irradiance (GHI) was computed from the lidar-derived elevation model of Cebu City using the Geographical Resources Analysis Support System (GRASS). It is shown that annual variation in average temperatures in Cebu is generally less than $5^{\circ} \mathrm{C}$. Mean UHI temperatures in Cebu City do not show a clear trend over time, but categorizing data by season, namely the rainy season (June - November), the cool dry season (December - February), and the hot dry season (March - May), permits the emergence of a pattern. Surface temperatures for the cool dry season and hot dry season show a linearly increasing trend with $\mathrm{R}^{2}$ values of 0.916 and 0.514 , respectively. This study further investigates the temporal change in the degree and extent of the UHI in Cebu City by analyzing LST maps. Regression analysis is done to determine how LST is affected by the distribution of vegetation (NDVI) and built-up (NDBI), and the seasonal variation in solar radiation through the GHI.
\end{abstract}

\section{INTRODUCTION}

The urban heat island (UHI) effect describes the phenomenon in which urbanized areas have comparatively higher air and/or land surface temperatures than the surrounding rural areas (Landsberg, 1981, Oke, Mills, Christen, Voogt, 2017). It is characterized by the bulging of the spatial temperature profile around the location of the urban area. The temperature difference between the urban and the rural areas typically occurs after sunset and achieves a maximum 2-3 hours later. The UHI effect is stronger in nighttime than in daytime (Kim, Baik, 2005). The effect is apparent when the sky is clear of clouds and the wind is calm (Magee, Curtis, Wendler, 1999).

The UHI effect arises from a complex interplay of various factors such as urban design, skyview factor, building materials, solar radiation, wind speed, cloud cover, pollution, etc. Memon et al. (2008) classified these factors into controllable and uncontrollable factors. Controllable factors are those associated with anthropogenic influence such as urban design, building materials, sky view factor, population growth, etc. Uncontrollable factors are those factors that are controlled by nature such as solar radiation, wind speed, cloud cover, etc. Memon et al. (2008) also mentioned categorization of these factors into temporary effect factors such as wind and cloud cover, permanent effect factors such as building design and materials and sky view factor, and cyclic effect factors such as diurnal conditions and seasonal meteorological phenomena.

Solar radiation is the primary driver of the earth's climate (Stephens, L'Ecuyer, 2015) which responds in global, regional, local, and microclimatic regimes depending on the land surface configuration (Zhou, Rybski, Kropp, 2017). As solar radiation strikes at the top of the atmosphere, fractions of it are reflected, transmitted, absorbed or scattered. In the global scale, 55\% of the incident radiation reaches the earth's surface mostly in the visible spectrum. This radiation is responsible for the energetics of the urban heat island (Oke, 1982). The UHI effect is the microclimatic response of an urbanized area to the incident radiation and to the anthropogenic heat released from airconditioning units, industrial installations, human metabolism, and other man-made sources. Only a small fraction of the heat from the solar radiation warms the environment directly while a large part of it is absorbed and stored by the complex built-up structure of the urban environment. In, contrast anthropogenic heat directly and instantly warms the environment. The extent at which energy is captured and stored depends on the controllable factors. Massive urban structure cramped in a small space captures large amount of heat because of its low albedo due to its street canyon configuration and the building materials used in the construction of this structure. Heat transfer and energy conservation processes such as conduction,

\footnotetext{
* Corresponding author
} 
convection, and radiation are all at play among the different urban units ${ }^{1}$.Warming occurs from sunrise until the late afternoon when the environment begins to cool down. The heat stored in urban built-up structure is slowly released, the rate of which depends on the material and configuration of the urban environment. Heat release in areas of street canyon configuration is slower due to low sky view factor compared to open spaces.

Another factor that contributes to UHI is the loss of vegetation in cities and the subsequent result of low evapotranspiration, which is supposed to cool the environment. Temporary effect factors cloud cover and wind also influence UHI effect. Cloud cover reduces solar radiation flux. On the other hand, clouds also cause greenhouse effect which warms the area. This is especially apparent in the high-latitude regions. Convective cooling from the wind and related factors are supposed to decrease the amount of heat in an area. However, the urban structure's high roughness causes wind speed to slow down impeding convective heat removal (Kim, Baik, 2005).

The cyclic effect factors introduce cyclic variation of the UHI. Changing heat flux associated with the 11-year solar cycle, the earth's orbit around the sun, and its rotation about its axis result in seasonal patterns in UHI. In addition, seasonality of the UHI can be attributed to the amount of water, which helps lower the temperature through evaporative cooling, in the hydrologic cycle. Anthropogenic heat release also follows cyclic rhythm because human affairs are organized according to some schedules. Since our activities are scheduled on a weekly basis, for example, day-of-the-week variability (DOWV) of the UHI has been observed (Simmonds, Keay, 1997).

In this paper, we present results of our study of the UHI effect in Cebu City taking into account vegetation, urbanization, and the amount of solar radiation as measured by the global horizontal irradiance (GHI). Seasonal variation of the land surface temperature (LST) and GHI will be discussed.

\section{STUDY AREA}

Cebu City is a highly urbanized city located in the middle of the eastern coast of the island province of Cebu, in the Central Visayas Region of the Philippines. It is the seat of the provincial government although the city itself retains political independence from the provincial government. It is comprised of 80 barangays subdivided into two congressional districts. Barangays closer to the coast are generally smaller, more densely populated, and primarily residential or industrial while barangays towards the northwest are generally larger and less economically developed (Figure 1).

A feature of Cebu City, which is common to many cities and municipalities in the province of Cebu, is that its administrative boundary encloses an area with a large variation in elevation, going from sea level in the small, densely packed coastal barangays, to elevations of up to 900 meters above sea level towards the mountainous central spine of the island of Cebu. These mountain barangays generally have much smaller population densities, and although the primary source of livelihood is agriculture, the landscape at these higher elevations does not lend itself well to widespread cultivation.

${ }^{1}$ Urban unit as defined by Oke et al. (Oke, Mills, Christen, Voogt, 2017) is the repeating combination of materials and arrangement of active surfaces into an urban structure.

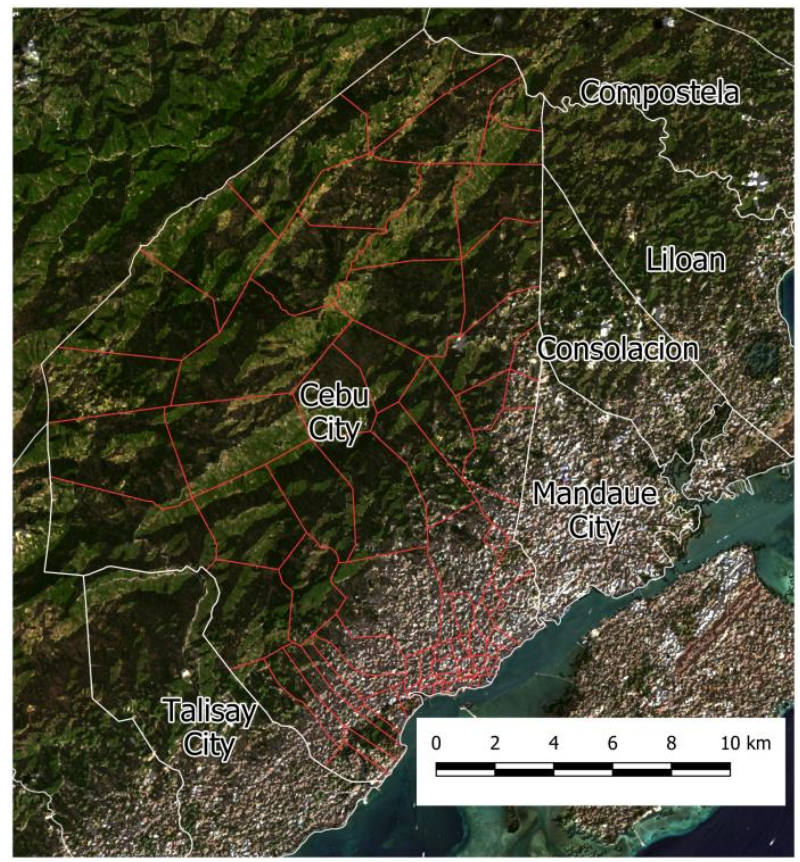

Figure 1. Satellite image of Cebu City showing the barangay boundaries (in red) and the adjacent cities and municipalities.

Due to the SE-NW orientation of the elevation gradient of the mountains of central Cebu, there is large variation in solar radiation incident on these rural barangays at higher elevations, whilst the urbanized barangays of the coastal lowlands receive relatively uniform insolation. This presents a unique challenge in that it is difficult to isolate the controllable (i.e. anthropogenic) and uncontrollable factors that affect land surface temperatures on a city-wide basis.

\section{METHODS}

\subsection{NDVI and NDBI}

There are many ways to describe the surface characteristics of a land area in remote sensing. The two useful remotely sensed characterizations of the land surface useful in this study are the Normalized Difference Vegetation Index (NDVI) and the Normalized Difference Built-up Index (NDBI) which are indicators of the degree of vegetation and land surface modification, respectively.

The NDVI is an index that estimates chlorophyll presence based on a surface area's relative reflectivity in the red and near
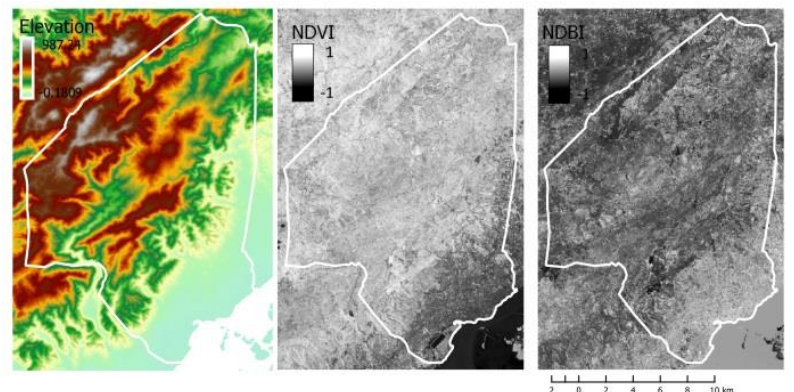

Figure 2. The elevation, and typical NDVI and NDBI data for Cebu City. 
infrared (NIR) wavelengths of the electromagnetic spectrum (Carlson, Gillies, Perry, 1994). The NDVI raster is derived from the red and NIR channels of multiband remotely sensed imagery by

$$
N D V I=\frac{(N I R-R)}{(N I R+R)}
$$

where $N I R=$ near infrared reflectance

$R=$ red reflectance

This results in a raster with pixel values ranging from -1 to 1 where values less than zero correspond to freestanding bodies of water, low positive values correspond to bare earth or rock, and values of 0.2 and above correspond to increasing densities of vegetation.

The NDBI was used as a measure of the degree of urbanization, which is characterized by the abundance of well-developed built-up areas. The NDBI can be computed from multiband remotely-sensed imagery, this time exploiting the fact that manmade surfaces tend to have higher reflectance in the short wave infrared (SWIR) than in the NIR wavelengths. The NDBI is thus calculated as

$$
N D B I=\frac{(S W I R-N I R)}{(S W I R+N I R)}
$$

where $S W I R=$ short wave infrared reflectance $N I R=$ near infrared reflectance

Resulting raster values will range from -1 to 1 where higher values are indicative of larger rates of anthropogenic land surface modification.

Remotely sensed Landsat data products, provided by the United States Geological Survey - Earth Resources Observation Systems (USGS EROS), were processed to obtain layers of NDVI and NDBI (Figure 2) for days with clear sky and no cloud cover (Project GUHeat, 2019). Appropriate preprocessing of the datasets, such as atmospheric correction and calibration were done.

\subsection{LST}

Landsat 8 data were processed following Project GUHeat manual (Project GUHeat, 2019) to compute the land surface temperature (LST) rasters. As Landsat 8 data only goes as far back as 2013, only data from 2013-2019 with low cloud cover were examined, and dates with little to no cloud cover was used, with specific acquisition dates listed in Table 1 .

Difficulties arise in the number of datasets. Since the launch of Landsat 8 in 2013, the 16-day revisit rate should have provided

\begin{tabular}{|ccccccc|}
\hline \multicolumn{6}{|c|}{ Landsat 8 data used (Row: 113, Col: 053) } \\
\hline$\underline{\mathbf{2 0 1 3}}$ & $\underline{\mathbf{2 0 1 4}}$ & $\underline{\mathbf{2 0 1 5}}$ & $\underline{\mathbf{2 0 1 6}}$ & $\underline{\mathbf{2 0 1 7}}$ & $\underline{\mathbf{2 0 1 8}}$ & $\underline{\mathbf{2 0 1 9}}$ \\
& $02 / 18^{*}$ & $02 / 05^{*}$ & $01 / 23$ & $06 / 02$ & $10 / 27$ & $01 / 15$ \\
$03 / 06$ & $03 / 09$ & $03 / 27$ & $08 / 05$ & & $04 / 21^{*}$ \\
& & $04 / 10$ & $05 / 14$ & & & \\
& & & & & & \\
& & & & & & \\
& & & & &
\end{tabular}

Table 1. Capture dates of low-cloud Landsat 8 imagery.

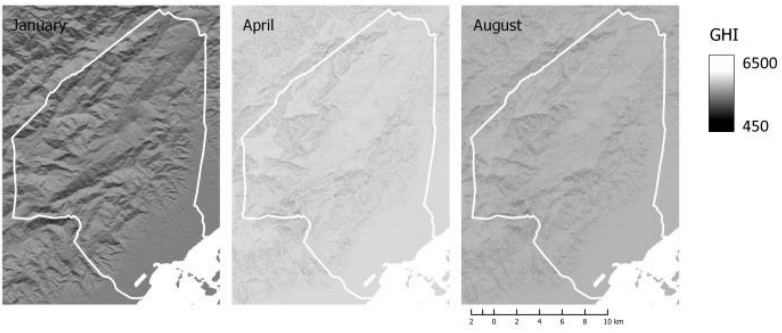

Figure 3. GHI in $\mathrm{W} / \mathrm{m}^{2}$ in Cebu City for representative months of the three different seasons.

ample amount of data for analysis. However, due to the persistence of cloud cover which affects image quality, most datasets were rejected resulting to a fairly small number of datasets available for analysis with large temporal gaps as shown in Table 1. Data from legacy Landsat satellites (Landsat 5 and 7) were also considered (Andales, 2016, Schaap, 2017).

\subsection{GHI}

Global Horizontal Irradiance (GHI) is a measure of the amount of radiant energy from the sun incident on the Earth's surface. It is a function of relative location and solar angles and local geographical morphology, and is often affected by atmospheric conditions like cloud cover or particulate matter in the atmosphere. Direct measurements with high spatial accuracy can be difficult to implement, as both access and opportunity can be limited, but GHI can be modelled using precise topographical information, geographic location, and astronomical information (Reno, Hansen, Stein, 2012).

Maps of average daily GHI per month for Cebu City (Figure 3), which were processed from georeferenced digital elevation maps using r.sun in the GRASS plugin in QGIS (GRASS Development Team, 2015), were obtained from the Phil LiDAR 2-REMap ${ }^{2}$.

\subsection{OLS Regression}

Ordinary least squares (OLS) regression is a powerful statistical tool that allows for the estimation of the linear relationship between a dependent variable and a set of explanatory variables. The method of OLS estimates a set of coefficients for the explanatory variables that minimizes the sum of the squared difference between the model's prediction and the observed data.

The coefficient of determination or the $\mathrm{R}^{2}$ value of the regression ranges from 0 to 1 , with unity describing a perfect linear fit. The Akaike information criterion (AIC) is also an indicator that, while not in itself a measure of the goodness of fit, allows for the comparison of different models. Models with lower values of the AIC indicate a balance between the fit and simplicity of the model. AIC, when coupled with $\mathrm{R}^{2}$ values allows for the evaluation of model quality. OLS regression analysis was done to determine the dependence of the LST to NDVI, NDBI and GHI over the five-year period from 2014 to

${ }^{2}$ Phil LiDAR 2 or 'Detailed Resources Assessment using LiDAR Surveys' was a nationwide program funded by the Department of Science and Technology (DOST) of the Philippine Government. REMap or Philippine Renewable Energy Resource Mapping Using LiDAR Surveys is one of the component projects of Phil LiDAR 2. 
2019.These products were generated from Landsat 8 data as enumerated in Table 1.

\section{RESULTS AND DISCUSSION}

\subsection{Long-term Temporal Evolution}

LST maps of Cebu City shows that coastal barangays generally have higher temperatures. These barangays are highly urbanized and clearly exhibit the UHI effect. We delineated the growth of the spatial extent of the UHI from 1989 to 2016 using the available datasets of good quality $(<30 \%$ cloud cover). Since Mandaue City is contiguous to Cebu City and both are highly urbanized, the two cities were considered as a single raster. The spatial extent of the UHI is estimated by determining the median between the lowest temperature in the rural area and the highest temperature in the low-lying urban area within the contiguous extent of Cebu and Mandaue Cities. The pixels with temperatures above this median value are used to approximate the extent of the urban heat island (see

Figure 4). These areas show a gradual yet significant increase in the spatial extent of the heat island over the past few decades (Schaap, 2017). For the 27 - year period, the area of the CebuMandaue City UHI has been expanding at the rate of about $0.121 \mathrm{~km}^{2}$ per month.

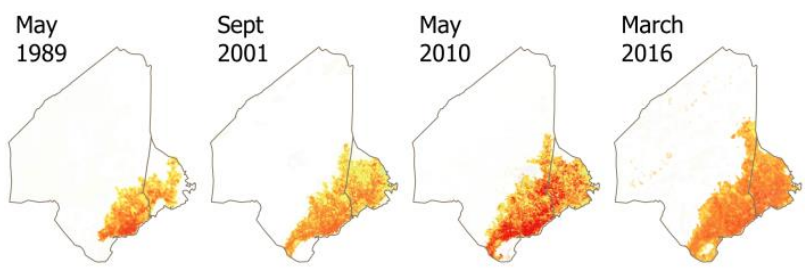

Figure 4. The extent of the Cebu City - Mandaue City urban heat island for select dates.

The mean temperature within this delineated UHI is also varying with no visible pattern, perhaps due to the weather conditions and other factors. However, sorting the mean temperature by season according to the seasonal classification for Cebu City by the Philippine Atmospheric, Geophysical and Astronomical Services Administration (PAGASA), namely the cold dry season that runs from December to February, the hot dry season occurring from March to May, and the wet rainy season in the months of June to November, shows a trend of rising average temperatures for the cool dry and hot dry seasons over the 27- year period.

The available data shows a temperature increase of $0.0516^{\circ} \mathrm{C}$ per month or $0.6192{ }^{\circ} \mathrm{C}$ per year since 2002 for cool dry season temperatures, and a temperature increase of $0.0151{ }^{\circ} \mathrm{C}$ per month, or $0.1812{ }^{\circ} \mathrm{C}$ per year since 1989 during the hot dry season, with $\mathrm{R}^{2}$ values of 0.9160 and 0.5140 respectively (see Error! Reference source not found.). Rainy months show consistently lower LST, but does not exhibit significant temporal trend $\left(\mathrm{R}^{2}=0.091\right)$.

\subsection{Seasonal variation of GHI}

Despite the large variation in elevation and indices such as the NDVI and NDBI across the city (Figure 2), the spatial variation in the GHI is small, regardless of the season. The largest deviation occurs in the cool dry months of December to February, where average daily GHI is $3.8 \mathrm{~kW} / \mathrm{m}^{2} \pm 12.7 \%$
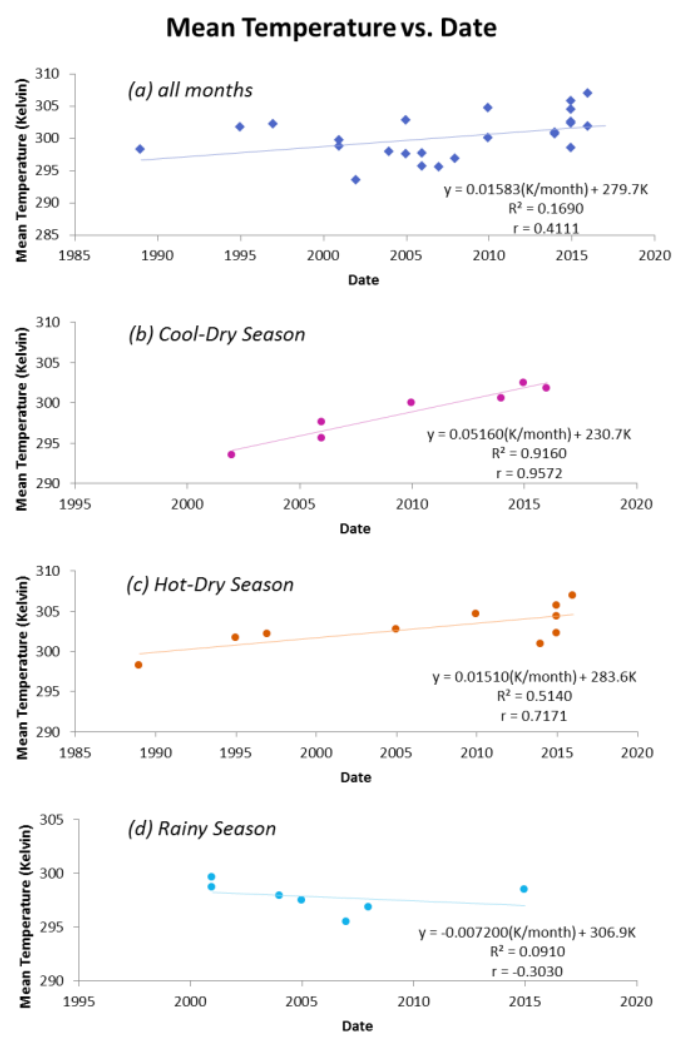

Figure 5. Seasonal trends in the mean UHI temperature.

whereas the hot dry months of March to May and the rainy season in June to November had GHIs of $5.4 \mathrm{~kW} / \mathrm{m}^{2} \pm 4.5 \%$ and $4.3 \mathrm{~kW} / \mathrm{m}^{2} \pm 4.6 \%$, respectively (Figure 6). A clear difference can be observed in the seasonal average. Cebu City, as a whole, gets the most sunlight in the hot dry summer months and the least during the cool dry season.

This seasonal GHI variation does not seem to directly correspond to LST as can be seen in Figure 7, which shows representative LST maps per season. While GHI values are higher for the rainy season than for the cool dry season, the LSTs exhibit the opposite trend. It seems that the greater insolation was offset by the cooling effect of water and cloud cover.

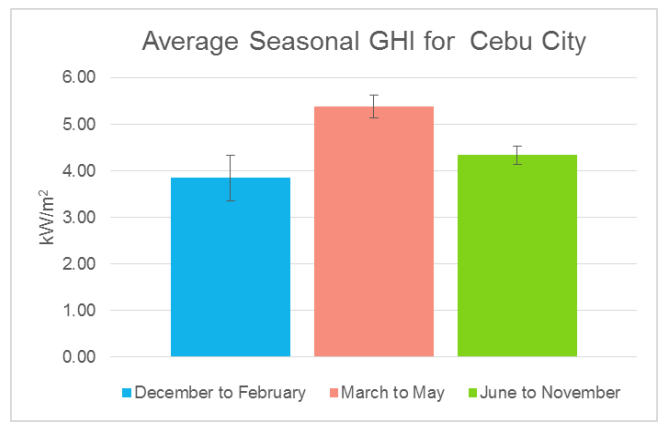

Figure 6. Average and standard deviation of GHI inCebu City per season: cool dry season (December to February), hot dry season (March to May), and wet season (June to November) 

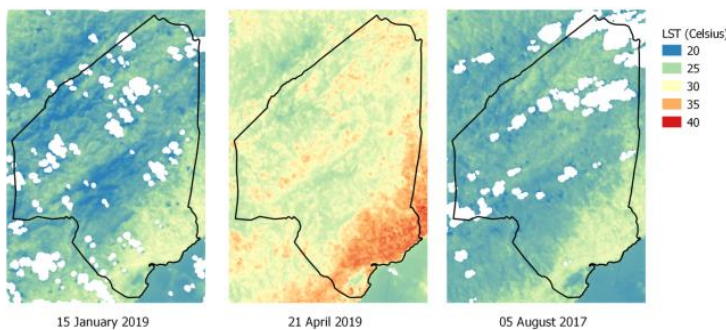

Figure 7. LST maps of Cebu City for dates representative of the three seasonal classifications of Cebu.

At the barangay level, the correlation coefficient between LST and GHI is higher in March to May and June to November than during the cold dry months of December to February although the scatter plots (see Figure 8) for all three seasons suggest a roughly linear relationship.

The density of the clustering on the high GHI / high LST end of the scatter plots suggests a saturation effect where temperatures approach a ceiling value for a certain range of GHI. Beyond 5.5 $\mathrm{kW} / \mathrm{m}^{2}$ in the summer, many barangays have a maximum temperature near $32^{\circ} \mathrm{C}$, and beyond $4.4 \mathrm{~kW} / \mathrm{m}^{2}$ in the rainy season, barangays reach a maximum temperature near $28^{\circ} \mathrm{C}$. This effect was not observed in the cool dry months.

This suggests that in the summer and the rainy season the barangays exhibit similar temperature-irradiance relationship, only that in the rainy season cooling effect of water suppresses heating. In the cool dry season, temperature-irradiance relationship is not well defined.

A closer look at the data seems to show that these saturation effects occur for the small, low elevation urban barangays. It is worth noting that the barangays of Cebu City have non-uniform
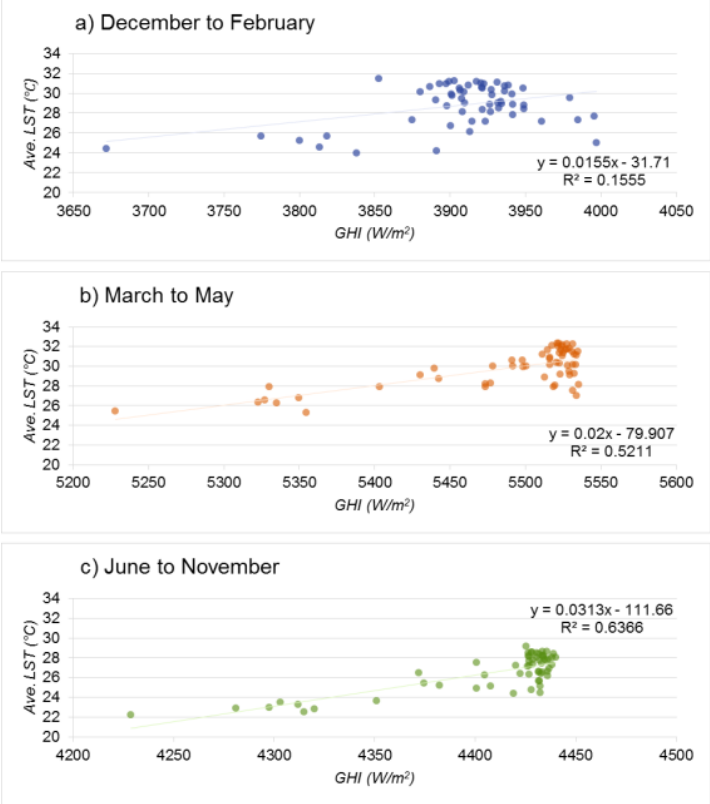

Figure 8. LST vs. GHI for the barangays of Cebu City in the a) cool dry season, b) hot dry season, and c) wet season. elevation, composition, and size, and an attempt to reduce the data loss in the spatial averaging is made in the analysis in the following section.

\subsection{Regression Analysis}

Due to concerns of varied spatial resolutions of the datasets, the spatial extent of the study area, and the availability of computing power, the study area was subdivided into 120 by $120 \mathrm{~m}$ grid cells.

This size was selected because while the thermal bands of Landsat 8 originally have a resolution of 100 by $100 \mathrm{~m}$, they are resampled to 30 by $30 \mathrm{~m}$ in the downloadable level 1 data products to match the other image bands, and the selected grid size contains whole pixels and reduces further aliasing and/or averaging issues. The grid size was also chosen so as to keep the number of data points manageable, reduce the weighting of the analysis towards the smaller barangays, and as it is approximately one fourth of the area of the smallest barangay, it still keeps the analysis relevant on the local government administrative level.

An exemplar of the averaged data for the cool dry season is shown in Figure 9. The implications of what the NDVI and NDBI values represent necessarily means that there may exist some correlations between them.

Scatter plots of NDBI against NDVI show that there is good negative linear correlation between the two. Furthermore, if the scatter plots are categorized by elevation (see Figure 10), the correlation between both variables is stronger at Cebu City's higher elevations, and the spread of data points is greatest at elevations at or below 100 meters, where all highly urbanized barangays are located.

This indicates that for these areas with a high density of buildings and anthropogenic land modification, the relationship between NDBI and NDVI are not as strictly straightforward as in the more vegetated highlands.

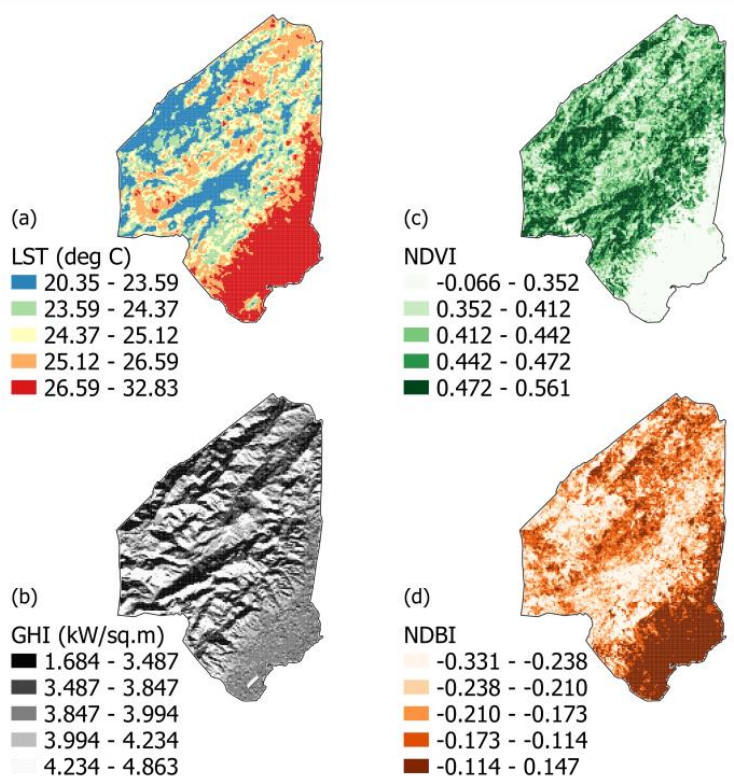

Figure 9. Seasonal averages of a) LST, b) GHI, c) vegetation, and d) built-up indices in Cebu City for the cool dry season, resampled to a $120 \times 120 \mathrm{~m}$ grid. 

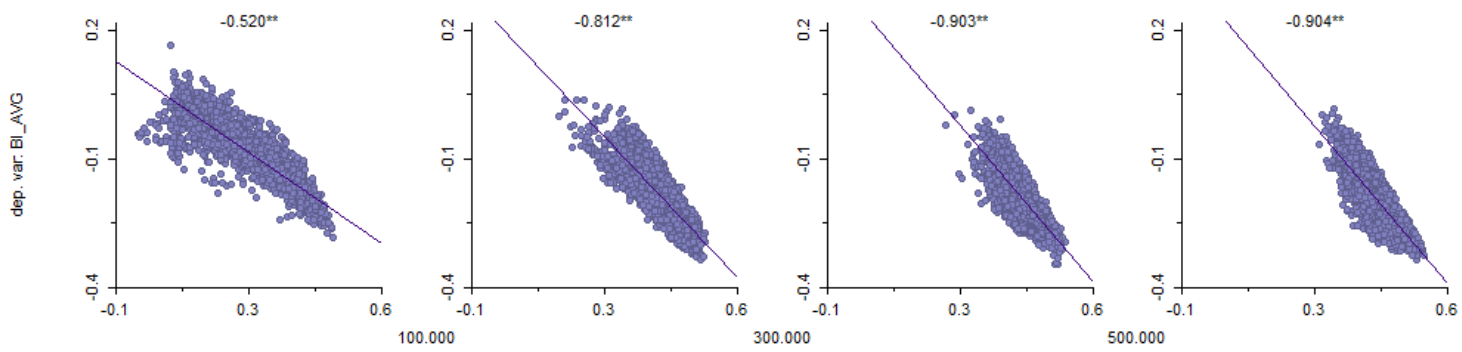

Figure 10. Scatter plot of NDBI vs. NDVI, categorized by elevation.

As a way to gain some insight into the differences in solar irradiance between the flat urban lowlands and the mountainous rural barangays, we look at scatter plots similar to those in Figure 8, but at higher resolution.

Figure 11 shows scatter plots of LST vs. GHI categorized by season and elevation. From top to bottom, the graphs show the cool dry season (season 1), the hot dry season (season 2), and the rainy season (season 3). From left to right, they are categorized by elevation from 0 to $100 \mathrm{~m}, 100 \mathrm{~m}$ to $300 \mathrm{~m}, 300$ $\mathrm{m}$ to $500 \mathrm{~m},>500 \mathrm{~m}$.

We can see that for elevations of $100 \mathrm{~m}$ or less, there is little variation in irradiance for a wide range of temperatures (see Figure 11). At higher elevations, a linear function fit would have to have a much lower slope, although it is fairly consistent for elevations above $100 \mathrm{~m}$.

The temperature saturation effects observed in Figure 8 can also be observed here, and is especially marked in the first column of scatter plots, where elevation s less than 100 meters. It can also be observed to some extent at the higher elevations for the hot dry season 2 and the cool wet season 3, but less so in the cool dry season 1 . This suggests that the saturation may be a result of material properties in the low-lying urban barangays.

Ordinary least squares regression was performed using average seasonal values and a summary of the $\mathrm{R}^{2}$ values, the log likelihood, and the Akaike information criterion (AIC) is presented in Table 2 .
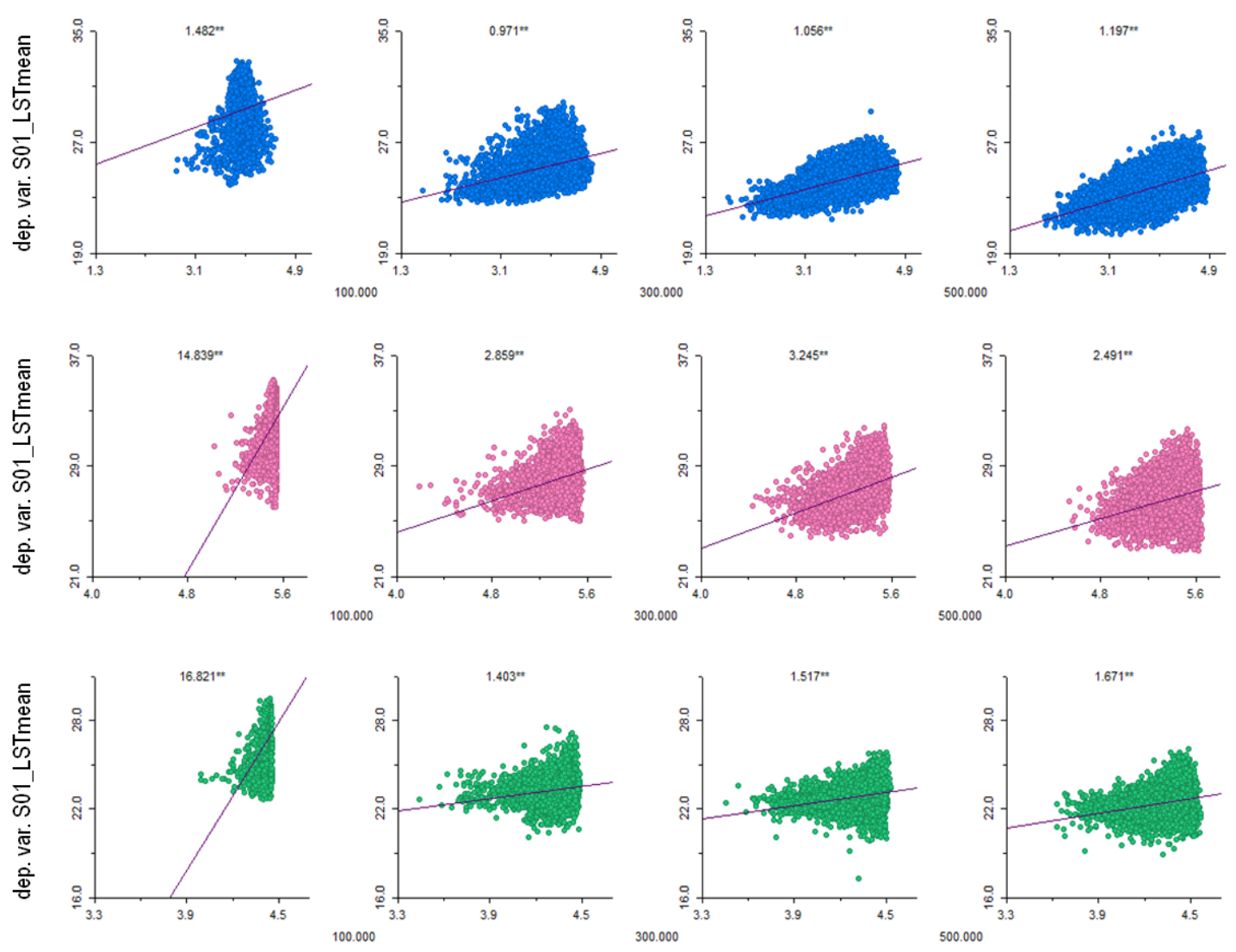

horizontal categories: elevation, independent variable: $\mathrm{GHI} \mathrm{kW} / \mathrm{sqm}$

Figure 11. Scatter plots of LST vs. GHI, categorized vertically by season and horizontally by elevation. 


\begin{tabular}{|c|c|c|c|}
\hline $\begin{array}{l}\text { Season } 01 \text { : } \\
\text { Dec-Feb }\end{array}$ & $R^{2}$ & $\begin{array}{c}\text { Log } \\
\text { likelihood }\end{array}$ & $A I C$ \\
\hline$N D V I$ & 0.588788 & -6642.87 & 13289.7 \\
\hline$N D B I$ & 0.605282 & -6559.80 & 13123.6 \\
\hline$G H I$ & 0.017106 & -8410.92 & 16825.8 \\
\hline$N D V I+N D B I$ & 0.627945 & -6439.83 & 12885.7 \\
\hline$N D V I+G H I$ & 0.603263 & -6570.15 & 13146.3 \\
\hline$N D B I+G H I$ & 0.610088 & -6534.95 & 13075.9 \\
\hline $\begin{array}{l}N D V I+N D B I+ \\
G H I\end{array}$ & 0.636145 & -6394.61 & 12797.2 \\
\hline $\begin{array}{l}\text { Season } 02 \text { : } \\
\text { Mar - May }\end{array}$ & $R^{2}$ & $\begin{array}{c}\text { Log } \\
\text { likelihood }\end{array}$ & $A I C$ \\
\hline$N D V I$ & 0.545512 & -6940.72 & 13885.4 \\
\hline$N D B I$ & 0.606514 & -6648.29 & 13300.6 \\
\hline$G H I$ & 0.298370 & -7821.78 & 14647.6 \\
\hline$N D V I+N D B I$ & 0.613223 & -6613.39 & 13232.8 \\
\hline$N D V I+G H I$ & 0.567076 & -6842.00 & 13690.2 \\
\hline$N D B I+G H I$ & 0.632108 & -6511.82 & 13029.6 \\
\hline $\begin{array}{l}N D V I+N D B I+ \\
G H I\end{array}$ & 0.633627 & -6503.43 & 13014.9 \\
\hline $\begin{array}{l}\text { Season } 03 \text { : } \\
\text { Jun - Nov }\end{array}$ & $R^{2}$ & $\begin{array}{c}\text { Log } \\
\text { likelihood }\end{array}$ & $A I C$ \\
\hline$N D V I$ & 0.636995 & -6063.08 & 12130.2 \\
\hline$N D B I$ & 0.586731 & -6326.14 & 12668.9 \\
\hline$G H I$ & 0.201815 & -7661.38 & 15326.8 \\
\hline$N D V I+N D B I$ & 0.648036 & -6000.42 & 12006.8 \\
\hline$N D V I+G H I$ & 0.646508 & -6009.21 & 12024.4 \\
\hline$N D B I+G H I$ & 0.602461 & -6247.42 & 12500.8 \\
\hline $\begin{array}{l}N D V I+N D B I+ \\
G H I\end{array}$ & 0.656088 & -5953.48 & 11915.0 \\
\hline
\end{tabular}

Table 2. Summary of OLS Regression.

Of the three variables, the NDBI is the most effective single predictor of LST, followed closely by NDVI for the cool dry season 1 and the hot dry season 2 . In the rainy season 3, NDVI has a better fit.

GHI in univariate regression is insufficient for modelling LST and the model for all three seasons has small $\mathrm{R}^{2}$ values, but is especially so during season 1 where it is 0.017106 , which is much smaller than in either of the other seasons. Adding it as a covariate to NDVI or NDBI, or both, improves the fitness of the model as can be seen by the increase in the $\mathrm{R}^{2}$ and the $\log$ likelihood, and the decrease of the AIC.

$\mathrm{R}^{2}$ values when NDVI is the sole independent variable are all greater than 0.5 , with season 3 having the best fit. Adding the GHI as a covariate for the model increases the $\mathrm{R}^{2}$ and decreases the AIC values for all three seasons, with the season 3 model showing the most improvement, with a decrease in the AIC of $9.9 \%$.
NDBI also has significant $\mathrm{R}^{2}$ values in univariate regression, the model performing better than NDVI for the dry seasons 1 and 2. Adding the GHI as a covariate improves model performance across the board, with season 2 having the best fit of the three seasons, but comparable drops in the AIC of 10\%, $9.8 \%$, and $9.9 \%$ for seasons 1,2 , and 3 , respectively. Although the decrease in the AIC is lowest for season 2, it has the greatest increase in the $\mathrm{R}^{2}$.

The NDBI + GHI model seems to work better for season 2 than the other two seasons, performing much better than the NDVI + GHI model, which indicates that the presence of built up areas and the intensity of solar radiation is more predictive of land temperature. This in turn may indicate that in the hot dry season tempering effect of vegetation on land temperatures is at its least.

Using NDVI and NDBI as covariates produces a model that performs better than NDVI + GHI, NDBI + GHI, or any of the univariate regressions, except for season 2 , where NDBI + GHI has a better fit with a higher $\mathrm{R}^{2}$ value. When using all three, NDVI, NDBI, and GHI as covariates, the AIC values are lower by $9.9 \%$ for the cool seasons 1 and 3, and by $9.8 \%$ for season 2 , as compared to AIC values with just NDVI + NDBI. While the AIC decrease is least for season 2, the percent increase in $\mathrm{R}^{2}$ is greatest. This marked increase in fit for season 2 when GHI is added as a covariate suggests that received solar radiation is a more significant factor during the hot dry season than it is during the cool dry or rainy seasons.

Despite the poor performance as the single model variable in season 1, adding GHI as a covariate along with both NDVI and NDBI improves the fitness of the model, both increasing $\mathrm{R}^{2}$ values and decreasing the AIC.

\section{CONCLUSIONS}

In this paper, we showed that the spatial extent of the urban heat island in Cebu City is increasing. If the contiguous neighboring city of Mandaue is included, UHI is expanding at the rate of $0.121 \mathrm{~km}^{2}$ per month since 1989 . The average LST is also increasing. The rate of increase is $0.6192{ }^{\circ} \mathrm{C}$ per year since 2002 during the cool dry season (December to February) and $0.1812{ }^{\circ} \mathrm{C}$ per year during the hot dry season (March to May) since 1989. There is no identifiable trend for the temperature increase during rainy season (June to November).

The GHI showed little spatial variation regardless of the season. The largest deviation occurs in the cool dry months of December to February, where average daily GHI is $3.8 \mathrm{~kW} / \mathrm{m}^{2}$ $\pm 12.7 \%$ whereas the hot dry months of March to May and the rainy season in June to November had GHIs of $5.4 \mathrm{~kW} / \mathrm{m}^{2} \pm$ $4.5 \%$ and $4.3 \mathrm{~kW} / \mathrm{m}^{2} \pm 4.6 \%$, respectively.Cebu City, as a whole, gets the most sunlight in the hot dry summer months, and the least during the cool dry season. While GHI values are higher for the rainy season than for the cool dry season, the LSTs exhibit the opposite trend. This can be explained by the cooling effect of water during the rainy season. At the barangay level, the correlation coefficient between LST and GHI is higher in March to May and June to November than during the cold dry months of December to February.

Regression analysis shows that there is good linear correlation between the two NDBI and NDVI. This is expected since the hitherto vegetated areas were converted into built-up areas.If 
the data are categorized by elevation, the correlation between both variables is stronger at Cebu City's higher elevations. At elevations of 100 meters and below, where high density of buildings is located and where complex anthropogenic land alteration is severe, the relationship between NDBI and NDVI is not well-defined.

\section{ACKNOWLEDGEMENTS}

This work is primarily funded by the Philippine Council for Industry, Energy, and Emerging Technology Research and Development-Department of Science and Technology (PCIEERD-DOST) through the project Geospatial Assessment and Modelling of Urban Heat Islands in Philippine Cities (Project GUHeat), Project No. 2048, 2019.

This research is a product of collaboration between the University of San Carlos Center for Geoinformatics and Environmental Solutions and the University of the Philippines Diliman Training Center for Applied Geodesy and Photogrammetry.

\section{REFERENCES}

Andales, R. Y. (2016). Correlation between the Normalized Difference Vegetation Index (NDVI) and the Temperature in Urban Heat Islands: A Case for Cebu City and Metro Manila, Undergraduate Thesis, Department of Physics, University of San Carlos, Cebu City, Philippines.

Carlson, T. N., Gillies, R. R., Perry, E. M., 1994: A method to make use of thermal infrared temperature and NDVI measurements to infer surface soil water content and fractional vegetation cover. Remote Sensing Reviews 9(1-2), 161-173.

GRASS Development Team, 2015. Geographic Resources Analysis Support System (GRASS) Software, Version 6.4. Open Source Geospatial Foundation. grass.osgeo.org

Kim, Y.-H., Baik, J.-J., 2005: Spatial and Temporal Structure of the Urban Heat Island in Seoul. Journal of Applied Meteorology 44(5), 591-605.

Kim, Y.-H., Baik, J.-J., 2004: Daily maximum urban heat island intensity in large cities of Korea. Theoretical and Applied Climatology 79(3), 151-164.

Landsberg, H. E., 1981: The Urban Climate. Academic Press, New York.

Magee, N., Curtis, J., Wendler, G., 1999: The Urban Heat Island Effect at Fairbanks, Alaska. Theoretical and Applied Climatology 64(1), 39-47.

Memon, R. A., Leung, D. Y., Chunho, L., 2008: A review on the generation, determination and mitigation of urban heat island', J Environtal Sciences 20(1), 120--128.

Oke, T. R., 1982: The Energetic Basis of the Urban Heat Island. Quarterly Journal of the Royal Meteorological Society 108(455), 1-24.

Oke, T. R., Mills, G., Christen, A., Voogt, J. A., 2017: Urban

Climates. Cambridge University Press, New York.
Project GUHeat Team, 2019. Image Processing Using QGIS. Part II, Training Manual, Geospatial Assessment and Modelling of Urban Heat Islands in Philippine Cities (Project GUHeat), Project No. 2048, Training Center for Applied Geodesy and Photogrammetry (TCAGP), Department of Geodetic Engineering, University of the Philippines, Diliman, Quezon City.

Reno, M. J., Hansen, C. W., Stein, J. S.,2012. Global horizontal Irradiance Clear Sky Models: Implementation and Analysis. SAND2012-2389, Sandia National Laboratories, Albuquerque, New Mexico and Livermore, California, USA.

Schaap, L. L. S. (2017). Analysis of the Evolution of the Urban Heat Island Effect and Vegetation Distribution Trend in the Cities of Cebu and Mandaue from 1989-2016 Landsat Data, Undergraduate Thesis, Department of Physics, University of San Carlos, Cebu City, Philippines.

Simmonds, I., Keay, K., 1997: Weekly cycle of meteorological variations in Melbourne and the role of pollution and anthropogenic heat release. Atmospheric Environment 31(11), $1589-1603$.

Stephens, G. L., L'Ecuyer, T., 2015: The Earth's Energy Balance. Atmospheric Research 166, 195-203.

Zhou, B.,Rybski, D., Kropp, J. P. 2017: The Role of City Size and Urban Form in the Surface Urban Heat Island, Scientific Reports 7(1), 4791. 